\title{
DESDOBRANDO A ONTOLOGIA OU A LITERATURA QUE PENSA O REAL
}

Maycon da Silva Tannis

\begin{abstract}
RESUMO
O presente texto visa demonstrar como o conjunto crítico e os escritos literários de Walter Benjamin integram um encaminhamento deontológico. Para isso trago autores que desenvolveram questionamentos em relação a aspectos formativos da Ontologia ou desenvolveram uma crítica aos seus efeitos. Nesse sentido, pretendo com esse texto uma exposição sobre o problema da ontologia, bem como um alinhamento entre dois exercícios de sua desconstrução, de modo a demonstrar, como, criticamente, Benjamin descreve o diagnóstico e, posteriormente, podemos observar a tentativa de romper com esse modelo que nos cerca e engloba.
\end{abstract}

Palavras-Chave: Deontologia. Teoria da História. Teoria da Literatura.

\section{UNDOING ONTOLOGY OR LITERATURE THINKING THE REAL}

\begin{abstract}
This paper aims to demonstrate how the critical set and the literary writings of Walter Benjamin integrate a deontological referral. To this end I bring authors who have developed questions about formative aspects of Ontology or have developed a critique of its effects. In this sense, I intend with this text an exposition on the problem of ontology, as well as an alignment between two exercises of its deconstruction. In order to demonstrate how, critically, Benjamin describes the diagnosis and, later, we can observe the attempt to break with this model that surrounds and encompasses us.
\end{abstract}

Keywords: Deontology. History theory. Literature theory. 
A preocupação com a ontologia, e com a destituição desta como única forma de compreender o mundo, parece ter sido um frequente mote de estudos em relação ao começo do século XX. Por um lado, a escalada Heideggeriana em busca da autenticidade e do Dasein em rompimento com os sistemas e pensadores anteriores abre as portas para uma crítica severa do modelo de pensamento que se assentava, até então, nas estruturas que para o autor filonazista, isolavam a existência inautêntica em uma mundanidade cotidiana e impediam o acesso do ente à sua forma mais autêntica e verdadeira, o Dasein.

Em sua crítica à historiografia, que não se pode destacar de um projeto maior, a sua crítica à ciência, onde o autor, ao contrário do que se disse, não tem seu primeiro rompimento na técnica, mas antes disso, Heidegger pretende destituir a ciência como o grande centro do pensamento e restituir a filosofia em sua primazia de geradora de um conhecimento autêntico e que rompa com a inautencidade do mundo (Mundanidade. Opacidade do mundo) que nada mais é que o terreno opaco por onde se move o homem, Uma vez que a modernidade completa o ciclo de fechamento na estrutura ontológica (BARASH, 1998, 80), a ciência particulariza a existência e mantém uma perenidade e estabilidade a partir dos conceitos. O projeto de Heidegger como anticientífico visa trazer à primazia do conhecimento a filosofia como era antes de Descartes. Uma vez que nesse desvelamento do ente os conceitos gerados necessitam de legitimação e confirmação do seu conteúdo em relação ao ente. De acordo com o que o ente é quanto ao seu conteúdo, assim o acesso a ele se dá. Permanecendo no exame do ato fundamental da objetivação, podemos perguntar sobre qual é a condição fundamental da sua realização. Como já visto a relação com o ente só é possível pela prévia iluminação e prévia condução da compreensão de ser como postura hermenêutica ontológica, tornando assim, segundo Heidegger, os passos da ciência, passos que se movem com ingenuidade. (HEIDEGGER, 2006, 45)

A "viragem" (Die Kehre) promovida por Heidegger com sua filosofia rumo ao Dasein, aponta sempre para a autenticidade da existência latente, no entanto isolada pelas estruturas do mundo da vida. Esse ponto nos é interessante pois 
há aqui um importante loca de convergência com a proposta de estudo da literatura, principalmente a que é composta nesse mesmo período e que seria mesmo uma característica da literatura, em sua vastíssima profundidade: tocar parâmetros existenciais e nos expor algo que não estava ali antes.

De modo a tratar desse tema a partir de escritos que se afastem do discurso filosófico, tomo aqui Virgínia Woolf em seu conto A Marca da Parede, Fiodor Dostoievsky, em seu conto Bobok, e Walter Benjamin em seu conto Mummerehlen e A Lontra bem como uma passagem pela sua teoria. Sem decair no puro comentário e na descrição, pretendo aproximar os três para ampliar as minhas considerações sobre ficção.

Considerando o exposto acima, é interessante notar de antemão um perigo que cerca a tentativa de aproximar dois autores que escreveram dentro e fora da literatura, sobre a literatura e sobre o mundo que os cercava: o perigo de (1) querer impor ao autor algo que ele nunca disse ou mesmo que não tenha ligação alguma com as múltiplas possibilidades de desdobramento que o texto carrega em si e (2) tentar aplicar a teorização para um fim estrito, quando o próprio sentido de se teorizar sobre a ficção (ou sobre o ficcional) aponta para a sua metacrítica enquanto ficcionalidade que rompe com as amarras do mundo e o expande com sua capacidade de hiper-realização do real.

A Marca na Parede ${ }^{1}$ é um breve conto que carrega em si o germe das histórias intermináveis. Em suas breves páginas vemos o questionamento entre dois momentos, de princípio e fim, a respeito do perguntar-se pelo perguntar e como a possibilidade de conhecer algo está intimamente ligado a todo o conhecimento. Interessante pensarmos que já no itinerário simples da história já temos uma complexa operação: ao observar uma marca na parede o narrador

\footnotetext{
1 "A Marca na Parede", de autoria de Virginia Woolf, foi publicado em julho de 1917, juntamente com o conto de Leonard Woolf "Three Jews" em Two Stories, a primeira publicação da Hogarth Press. Saiu (ligeiramente revisto) em edição separada, em julho de 1919 (E é esta edição que usarei, em sua tradução feita por hélio Pólvora) com novas revisões em Monday or Thursday (Londres: The Hogarth Press. 1919).
} 
vai e volta dentro da questão do que seria a marca e este motivo o leva a um profundo questionamento sobre o que é o conhecimento e o conhecer.

Já no princípio o narrador se fixa em uma espacialidade "Foi talvez em meados de janeiro que pela primeira vez levantei os olhos e via marca na parede."(WOOLF, 1992, 77), mas curiosamente essa espacialidade garante 0 que normalmente se rompe: a imobilidade, na tentativa de pensar sobre o que é a tal mancha o narrador se mantém imóvel, envolto em pensamentos e tentando articular possíveis correlações. A partir da inserção desse detalhe começa uma série de desdobramentos que fazem uma série de relações automáticas com a capacidade da fantasia, ou para ser mais preciso a capacidade de imaginar fantasiosamente um elemento de ficção, então, o reparar em um elemento (agora novo), uma mancha na parede "15 centímetros acima da cornija da lareira, começa-se a reparar no ambiente em volta subsumindo em forma de jogo de oscilação a consciência de vigília aos instantes de imaginação, o geralcotidiano ao particular da fantasia pessoal: "A velocidade com que nossos pensamentos nos invadem em torno de um novo objeto, levantando-o como formigas que carregam sua palha de maneira tão febril que logo a abandonam."2 Essa explosão de imagens capazes de ligar o particular ao geral é muito próximo à concepção de Benjamin sobre a imagem, mas interessante notar que o encadeamento de imagens descontínuas e com origens comuns dentro de um mesmo elencamento amplo e múltiplo de sentidos causados é a forma pela qual Woolf trabalha em seus contos ${ }^{3}$.

Então compreende-se que a marca na parede evoca imagens (1) físicas que remetem a situações cotidianas - como as cinzas, o fogo da lareira e a família que antes ocupava a casa e queria se mudar para mudar de estilo os móveis. e (2) imagens puramente mentais - como "Poderia me levantar, mas se me

\footnotetext{
2 WOOLF. Op. Cit. Página 77.

${ }^{3}$ Aqui me baseio na compreensão que Ana Carolina de Azevedo Guedes formula em seu estudo sobre a possibilidade de uma formatividade autobiográfica em Virgínia Woolf em seu conto "O Sol e o Peixe". Guedes compreende que o elencamento de imagens poéticas sequenciais funcionam como u conjunto, mesmo que para isso Woolf tome o não-sentido do mundo e a descontinuidade entre uma experiência e outra em um bojo um nível acima, o que a autora chama de imagerias. Cf. A metáfora como possibilidade autobiográfica: um breve ensaio. In Revista Entrelaces • V. 1 • No 10 • Jul.-Dez. (2017) • ISSN 1980-4571 (Disponível em http://www.periodicos.ufc.br/entrelaces/article/viewFile/11707/71518)
}

Doutorando (CNPQ) no Programa de pós-graduação em História Social da Cultura da Pontifícia Universidade Católica do Rio de Janeiro. Brasileiro, reside em Rio de Janeiro-RJ. E-mail: 
levanto e olho, teria uma em dez probabilidades de me certificar; pois, quando se faz uma coisa, ninguém sabe de que maneira aconteceu." ${ }^{4}$ Que mostra uma tensão sobre o que é visto e o que não é compreendido, mas a incompreensão não remete a um desentendimento, o que incluiria aí um terceiro elemento (Entre o objeto e a experiência dele) há a imaginação, o mecanismo que propicia a cognição da coisa, uma vez que não tocamos a coisa em si com a nossa compreensão. Nessa pequena redução temos duas permanências subsumidas dentro da escrita Woolf que podem passar despercebidas, primeiro lugar é a ancora constante do real, que se impõe a todo momento como um retorno à busca pela conclusão do que é a mancha, ou seja um sinal de realidade que se afirma sempre que a imagem é ativada como elemento de pensamento.

Benjamin, na escrita de seu conto Mummerehlen faz um caminho um pouco diferente, mas ainda no mesmo sentido. Já abrindo em estado metacrítico à experiência do literário, o autor toma uma pequena peça que nos ilustra a possibilidade exposta por Iser, de ligar a literatura a sua estrutura mais ampla e existencial:

\begin{abstract}
Numa velha rima para crianças aparece a Muhme Rehlen. Ora, como a palavra "Muhme" nada me dizia, essa criatura transformou-se para mim num espírito: a Mummerehlen. Tal mal entendido distorceu o mundo aos meus olhos. De um modo positivo, contudo, pois apontavame os caminhos para o seu interior. Qualquer pretexto the servia.(BENJAMIN, 1992, 145)
\end{abstract}

Benjamin, apesar de sua teorização a respeito da mímesis ser limitada ao domínio da mímesis como imitação ( $\mathrm{E}$ daí mesmo com a lacuna do que seria imitar, o real ainda detém peso paradigmático em sua compreensão.), temos uma abertura em seus textos literários que (1) rompem com a compreensão do próprio Benjamin, sobre a literatura, ao mesmo tempo em que (2) expõe logo de princípio os desdobramentos que a literatura pode gerar no real.

Por um lado, temos a experiência de infância que se molda a possibilidade de constituição de uma realidade que se alimenta de um sentido originário - No

\footnotetext{
${ }^{4}$ WOOLF. Op. Cit, 78.
}

Doutorando (CNPQ) no Programa de pós-graduação em História Social da Cultura da Pontifícia Universidade Católica do Rio de Janeiro. Brasileiro, reside em Rio de Janeiro-RJ. E-mail: 
caso, Muhme, que é uma palavra que pode significar tanto tia quanto qualquer parenta do sexo feminino por parte de mãe. - Para criar algo novo e que expande e desdobra esse real. Benjamin se apropria bem dessas imagens vindas de experiências mas que não se limita a elas. No caso, Muhme ou Mummerehlen, que se tem a dupla realização, enquanto real, ainda preso ao sentido correto da palavra Muhme e como ficção encarnada na Mummerehlen. Benjamin tem uma ligação especial com a experiência e, não à toa, traz suas experimentações ficcionais em torno de seu próprio passado, supostamente rememorado em seus contos publicados em jornal e mais tarde reunidos em volumes, sob a forma de coletânea de contos, por Theodor Adorno. Benjamin tem um ponto interessante de notar, pois a definição de todos os terrenos movidos pelo efeito metafórico, isto é, uma definição estrita sobre a amplitude da metáfora enquanto fenômeno, em Walter Benjamin decorrem mais fora de sua teorização a respeito da metáfora e em maior e mais larga escala, em sua teorização sobre o aparato cognitivo gerado pela imagem.

Para Jeanne Marie Gagnebin, a teorização de Benjamin a respeito da Mímesis se localiza no bojo de sua reflexão sobre a linguagem (GAGNEBIN, 1993.), com um espaço de 5 anos, Benjamin faz uma longa proposição em relação a possibilidade de compreensão da mímesis, uma vez que esse conceito não pode ser apreendido como um conceito puro, uma vez que sua propriedade não é estritamente analítica e ele não se realiza apenas no entendimento. Para a autora a exposição mais clara sobre a mímesis está em seus dois textos sobre linguagem (Da linguagem geral e da linguagem do homem [1916] e A tarefa do tradutor [1921]). Neste arco apresenta-se uma consideração sobre a origem da linguagem e aponta a ligação direta entre "linguagem divina" e linguagem humana, o que poderia ser visto na proposição de que na linguagem se encontravam a matéria e a verdade. Como exemplo tomo a consideração que Benjamin faz a respeito das práticas místicas e das relações com o divino que foram apostas à racionalidade e à ciência, mas que se encaminham no mesmo bojo da capacidade de conhecer, fato demonstrável pela sua interação com os "Arquivos de Linguagem": 


\begin{abstract}
Se essa leitura a partir dos astros, das vísceras e dos acasos era para o primitivo sinônimo de leitura em geral, e se além disso existiram elos mediadores para uma nova leitura, como foi o caso das runas, podese supor que o dom mimético, outrora o fundamento da clarividência, migrou gradativamente, no decorrer dos milênios, para a linguagem $e$ para a escrita, nelas produzindo um arquivo completo de semelhanças extra-sensíveis. Nessa perspectiva, a linguagem seria a mais alta aplicação da faculdade mimética: um médium em que as faculdades primitivas de percepção do semelhante penetraram tão completamente, que ela se converteu no médium em que as coisas se encontram e se relacionam, não diretamente, como antes, no espírito do vidente ou do sacerdote, mas em suas essências, nas substâncias mais fugazes e delicadas, nos próprios aromas. Em outras palavras: a clarividência confiou à escrita e à linguagem as suas antigas forças no correr da história (BENJAMIN, 1996, 112).
\end{abstract}

Curiosamente, a compreensão de Benjamin sobre a linguagem não está longe da gramatologia medieval que apresenta o aspecto sagrado da nomeação como instância criadora. Isto é, ao criar o mundo, Deus o faz a partir da palavra e a palavra tem validade de matéria e de existência. Esse paradigma existentivo se torna uma longa discussão que cobre os séculos $V$ até o início da Escolástica (Meados do século XII) No centro desta discussão a linguagem tinha uma potente capacidade criadora que se liga, de modo positivo a Adão, uma vez que dentro da mitologia cristã foi ele quem nomeou as "Coisas do mundo" em sua existência e em sua essência (Ousia), de modo que a preocupação da tradição gramática medieval estava para além da simples determinação da forma, mas a partir da formalização dos elementos, chegou a uma instância reflexiva da ideia e consequentemente, a determinação da essência dos elementos formadores do mundo da vida.

O domínio da linguagem, como forma e conteúdo, era uma abertura para estar próximo de Deus, uma vez que seria dado ao homem a capacidade de nomear o mundo da vida. ${ }^{5} \mathrm{O}$ hiato entre criar e conhecer era para Benjamin superado pela capacidade criativa da linguagem, em relação à aproximação, mas nunca chegada, ao nomos e por outro lado, a capacidade de ampliar o circuito de existência em torno do homem. Mas a compreensão da origem da linguagem para Benjamin não refletia o que era a linguagem contemporânea à

\footnotetext{
${ }^{5}$ Tal proposição é apresentada na Tese de Marshall McLuhan "O Trivium Clássico" lançado no Brasil pela editora É Realizações.
}

Doutorando (CNPQ) no Programa de pós-graduação em História Social da Cultura da Pontifícia Universidade Católica do Rio de Janeiro. Brasileiro, reside em Rio de Janeiro-RJ. E-mail: 
dele, já que para o autor o caráter nomeador da linguagem foi substituído por uma dimensão comunicativa, significativa e semiótica. De modo que para o autor, um retorno ao passado é impossível, mas a linguagem tem a possibilidade de se renovar na liberação da prisão da comunicação em um consequente ação no presente pela reflexão, o que levaria a uma constante busca da renovação da palavra e romperia com o peso que o mundo político tem sobre a existência, para isso a apresentação filosófica seria o meio pelo qual a palavra se libertaria, enquanto ideia, de seu âmago no cotidiano, da sua cotidianeidade, mas retomando a sua capacidade nominativa a partir desse movimento crítico de reflexão.(BENJAMIN, 1984.)

A teorização da linguagem, então, está sob o domínio do constante rompimento com o cotidiano e a demarcação de uma caracterização criadora da linguagem. Esse movimento duplo é o elemento chave para a compreensão da atribuição de Benjamin a mímesis como elemento formador da linguagem. Uma vez que a capacidade mimética humana não é substituída pelo pensamento abstrato, mas por conta do enfoque que se deu na escrita e na linguagem, para o autor então, tem-se que a iluminação profana do ato de leitura é possível encontrar uma proximidade com esses rompimentos dispostos e a característica chave da teoria mimética que se baseia em uma lógica da semelhança em contraponto com a compreensão identitária fornecida pela identidade. Para Gagnebin o caráter da semelhança não se dá por uma motivação de imitação, mas de uma mediação a partir do extrassensível:

Em vão procurar-se-ia uma similitude entre a palavra e a coisa baseada
na imitação. Saber ler o futuro nas entranhas do animal sacrificado ou
saber ler uma história nos caracteres escritos sobre uma página
significa reconhecer não uma relação de causa e efeito entre a coisa e
as palavras ou as vísceras, mas uma relação comum de configuração.
A imitação pode ter estado ou não presente na origem, ela pode se
perder sem que a similitude se apague. (GAGNEBIN, 1998, 98-99)

Daí o conceito de semelhança extrassensível, utilizado por Benjamin para definir a linguagem como o grau último da capacidade mimética humana e o arquivo, o mais completo, dessa semelhança extrassensível. 
O que não seria chocante uma vez que localizássemos a teorização mimética de Benjamin com uma continuidade com o pensamento Kantiano, ainda que rompa com ele por conta de sua teoria mimética trazer para dentro de si a experiência como ponto fundamental para a sua realização, em conjunto com a imaginação.

Benjamin também faz o caminho contrário dessa compreensão e compreende que o rompimento entre experiência é a terraplanagem necessária para a identificação entre o sujeito e o objeto.

Kant, sendo o primeiro filósofo a atribuir à imaginação uma característica constitutiva entre o sensível e o cognoscível, abre a possibilidade de compreender a imaginação não como um simples produto das relações externas, mas como formativo do mundo e pelo qual nós o compreendemos, estando ela antecedida pelos a priori do tempo e do espaço. Uma vez que às representações e à própria compreensão de mundo se impõe a mediação feita pela imaginação em relação à coisa em si, que nunca é tocada em definitivo pelas (três) faculdades do homem: A imaginação (como faculdade produtiva de conhecimento) é, com
efeito, muito poderosa na criação de uma outra natureza, por assim
dizer, do conteúdo que a verdadeira lhe dá. Nós nos entretemos com
ela quando a experiência parece muito cotidiana; e também
transformamos esta última - sempre se acordo com leis analógicas, é
claro, mas também segundo princípios que residem mais alto, na
razão. [...] isso faz com que nos sintamos livres do princípio de
associação (que é inerente ao uso empírico da imaginação), uma lei
segundo a qual, de fato, o material da natureza pode ser-nos
emprestado, mas com a possibilidade de o transformarmos em algo
inteiramente diverso, a saber, aquilo que ultrapassa a natureza. (KANT,
2016,212 )

Em Kant, se expõe a fratura que será colocada futuramente por Ricoeur e de modo mais sistematicamente concebido, por Hans Blumenberg, aqui tomo todo o tensionamento entre natureza e semelhança que gera uma profunda tensão. A tensão da semelhança se impõe como um a priori. E esta habilidade da semelhança é aproveitada por Benjamin em sua concepção e mimesis, mais ainda quando o autor pensa a capacidade mimética de subsumir as caraterísticas particulares no todo, o que nos remeteria à compreensão de que 
a dimensão mimética não se separa da dimensão semiótica da linguagem e esta ponte, por sua vez, nos leva à compreensão de que a Semelhança, como elemento formativo da mimesis em Benjamim, torna capaz a passagem de um símbolo linguístico a outro: a palavra, não sendo apenas símbolo tem uma aura evocativa de uma ou mais imagens. O que permite a apreciação da coisa designada pela palavra. ${ }^{6}$ No que a dimensão mimética da linguagem, que só pode ser chamada assim e não mais como um conceito estrito de mimesis, mas uma dimensão de constante mutabilidade e semelhança, esse tensionamento é interessante pois demonstra que, por um lado, temos a mimesis remetendo a um instante, enquanto a semiótica remete sempre à continuidade. A continuidade da ligação das palavras. Quando a semiótica, quando a continuidade falha, a linguagem - que comunica o pensamento e lugar da realização do pensamento - não se realiza. A poesia seria o mimema que para o autor operaria em sentido contrário, uma vez que ela não visa comunicar ou mesmo realizar de pronto um pensamento, ela se torna palco da pura tensão. Essa caraterística específica da poesia é um dos seus principais aspectos formativos o que nos leva à compreensão da poesia como um lugar de imagens sendo realizadas e mantidas no cume de seus tensionamentos.

No entanto é necessário grifar que em Benjamin não temos uma continuidade plena em relação a Kant, uma vez que Benjamin inclui dentro do jogo da imaginação uma proposta em contraponto à modernidade. Benjamin em sua compreensão de Imaginação como elemento formativo, inclui a experiência como um componente extra.

Esse componente extra foi tomando recentemente por Giorgio Agambem em seu livro Infância e História, onde o autor aproxima os conceitos de Infância e Linguagem a partir da chave da Experiência. A infância tomada como um lugar anterior ao sentido da palavra, admite a compreensão de que há a possibilidade de uma construção cognitiva que rompa com a continuidade da história e a partir da descontinuidade entre os pares linguagem e discurso, natureza e cultura,

\footnotetext{
${ }^{6}$ Daí a importância dada às onomatopeias por Benjamin, uma vez que ele identifica nelas uma forma de passagem de uma instância a outra da linguagem.
} 
continuidade e história, seja possível empreender um sentido. A infância se torna um constante experimento, ela torna possível, segundo Agamben, a possibilidade da recuperação da pura expressão, quando as palavras não se prendem a modelos analíticos ou a uma essencialização da subjetividade. A partir disso se desdobram os contatos e a ligação com o que Benjamin chama de divino. Agamben compreende essa viagem como um instante, um momento onde o discurso histórico se alinha ao imaginário, um momento no qual o tempo cronológico é rompido em sua homogeneidade e abre espaço para um salto originário (Ursprung) onde esse instante se abre e se desdobra na imagem poética, na pura tensão entre as forças que formam o movimento da dialética sem no entanto atentar uma acalmia à moda de Hegel.

A dialética na imobilidade (Dialektik im Stillstand) de Benjamin é notável, considerando que essa visão sobre a imagem já estava presente no ensaísta alemão, que em sua obra monumental, o livro Passagens o autor comenta que: "A Verdadeira imagem do passado perpassa veloz. O Passado só se deixa fixar como imagem, que relampeja irreversivelmente, no momento em que é reconhecido" (BENJAMIN, 2006, 289). A concepção de imagem em Benjamin se centra na compreensão de que na Imobilidade da imagem, capaz de sustentar a contradição de dois objetos avessos ao que se dá na realidade de uma apresentação (Darstellung) torna possível a compreensão mais pura de ambos os termos bem como uma escrita.

Para Benjamin, a única forma autêntica ${ }^{7}$ de escrever o passado é a partir do tensionamento propiciado pela escrita por imagens. Para o autor, a imagem anuncia um espaço de imobilidade conflitante, devido à contradição gerada pelos objetos em fricção, no caso, passado (tese) e presente (antítese). Por dois pontos, primeiramente, Benjamin trata de uma escrita da história que não é

\footnotetext{
${ }^{7}$ Aqui chamo a atenção para a necessidade de uma apreciação crítica do termo autêntico, onde eu uso como já definiu Heidegger, onde a autenticidade seria uma forma de romper com a estrutura ontológica de falseamento do real e escrever uma História que se encaminhasse para a completa realização do Dasein. Em Benjamin, apesar da incompletude de sua obra, há uma tentativa de romper com a teleologia do historicismo e bem como, com o sentido unívoco que a civilização imputa no pensamento historiográfico, mas, em deferência à Heidegger, Benjamin não estrutura seu pensamento na dispersão da Geschichte.
} 
permeada pela lógica do progresso. Assim, para Benjamin, não há uma experiência de futuro pré-programado, aparecendo, ao contrário como um dado de incerteza e imprevisibilidade.

Considere-se ademais que Benjamin se propõe a não diminuir a importância do presente quanto ao passado e, ao mesmo tempo, não reduzir o passado às expectativas do presente, o que Benjamin faz em várias escalas, como nas críticas ao Historicismo e ao próprio materialismo histórico. Para o autor, esses dois modos de conceber a história são compostos pela lógica do progresso processual.

Ao romper com a perspectiva cartesiana, Benjamin se propõe a escrever uma história que não trate mais dos avanços, mas sim das perdas e derrotas que deixaram apenas rastros e farrapos no caminho da história (BENJAMIN, 2006, 224). Deste modo, Benjamin se afasta do uso indiscriminado da cultura, que ele toma como sinônimo de aglomerado de barbárie (BENJAMIN, 2006, $502)^{8}$ :

Nunca houve monumento de cultura que não fosse também um monumento de barbárie. E assim como a cultura não está isenta de barbárie, não o é, tampouco o processo de transmissão da cultura. Por isso na medida do possível, o materialista histórico se desvia dela, Considera sua tarefa escovar a história a contrapelo. (BENJAMIN, 1994, 225)

Esse marcador de constante ir voltar no tempo, de buscar uma solução para o futuro na experiência do passado e não nas malhas do presente, do cotidiano, se mostram como antecipações. A metáfora-imagem em Benjamin é uma antecipação, por sua característica tensionada. E esta mesma estrutura tensionada que possibilita um encontro entre passado e futuro o que torna 0 presente uma série descontínua de retenções e uma série de [possibilidades de] antecipações e em cada um dos elementos que formam essas retenções e essas antecipações têm sua dimensão de presente e a mesma estrutura do nível

\footnotetext{
${ }^{8}$ A Saber: "Método deste trabalho: Montagem Literária. Não tenho nada a dizer. Somente a mostrar. Não surrupiarei as coisas valiosas, nem me apropriarei de formulações espirituosas. Porém, os farrapos, os resíduo: Não quero inventaria-los, e sim fazer-lhes justiça da única maneira possível: Usando-os."
} 
anterior. Benjamin explora isso de um modo interessante fora de sua teorização, em um texto literário seu, $A$ Lontra. Fala o autor "Nesses lugares, tem-se a ilusão do que ainda está para vir fazer parte do passado" (BENJAMIN, 1992, 139), o que se poderia tomar como uma amplitude contraditória se desdobra como uma maquinação do que Benjamin constrói ao longo de toda a sessão $\mathrm{N}$ das Passagens: a imobilização necessária do tempo em um ambiente especializado para a compreensão de suas forças formativas que somente se dispõem na tensão onde se realizam. E pensar que a experiência de espera em que se encontra a personagem do conto é o encontro tenso de dois tempos que, sendo paralelos, só são percebidos no passado da experiência dialética, em sua imobilidade, esses dois tempos - Messiânico (de constante espera e que não tem uma necessária realização) e da satisfação/alegria - se encontram em um arco temporal que se estica e culmina em um breve instante:

\begin{abstract}
Muitas vezes esperei eternamente em frente destas negras e insondáveis profundezas, na tentativa de aí descobrir a lontra. Quando por fim conseguia, era certamente apenas durante um breve instante, pois o inquilino luzidio voltava a desaparecer rapidamente na noite molhada. (BENJAMIN, 1992, 139)
\end{abstract}

Em poucas linhas é possível compreender que o fenômeno poético da escrita de Benjamin consegue formar uma Stimmung onde vários tempos, idas e vindas nos mesmos, se formam e se superpõem. Mas todos esses tempos são destruídos pelo presente da lontra. A dimensão do tempo messiânico, pautado nos sinais das experiências passadas e em um clima de constante espera e atenção à vinda do Messias/lontra e do tempo da felicidade, a dimensão temporal em que toda a espera se realiza na alegria, se desfaz como uma bolha de sabão. A força de mudança, que foge e escapa da relação causa e efeito, como na espera pela lontra, só se deixa ver no instante: $O$ instante tem o poder de caso alargado e imobilizado, abrir-se para o não-sentido, o instantâneo e as microinstâncias. O texto se torna um instante que tem no seu povir um sentido a ser construído.

Esta compreensão da relação Mímesis, Linguagem e Imagem formam, além da óbvia teorização que abarca um campo que não pode estar contido 
dentro dos parâmetros analíticos, um importante instrumento de desdobramento textual.

Como teórico Benjamin se mantém em uma esteira de Kant, rompendo com ele em pontos necessários e críticos à modernidade e bem como à tradição do Romantismo, uma vez que este toma o símbolo como apanhado e conteúdos estéticos. Benjamin considera, em deferência aos românticos, o símbolo como uma relação indissociável entre conteúdo e forma: "Na obra de arte o conteúdo e forma são um só: o assunto" (BENJAMIN, 1992, 145), onde o desmonte aponta para uma união com uma fissura.

Essa dicotomia - Imagem-Realidade - norteia os dois contos sem ser um elemento teleológico, no caso, só se percebe essa relação no desdobrar do texto. Em um terreno do texto que se executa no limite da ficção externa, como afirma Luiz Costa Lima (cf. COSTA LIMA, 2014.) e por se fazer em um caráter limítrofe quase esbarrando em uma criação anexa e que não diz respeito à força motriz da obra em si, o terreno dos desdobramentos do texto devem sempre ser tomados como tematizações teóricas que se nos apresentam como motivadas pelo texto e como metacrítica deste com a ambiência literária e com o próprio campo do ficcional, todo texto ficcional aponta, em seus possíveis desdobramentos teóricos para o campo onde ele patina e desliza, o terreno do ficcional. (ISER, 2013, 134) Assim cada ficção é uma entidade particular que se liga, metacriticamente ao campo teórico do fictício, ainda que essa não seja a motivação principal. A dicotomia fica mais clara quando se expõem os elementos de movimento, os agentes dessas duas instâncias são condensados em duas modalidades, por um lado os que buscam a verificação direta e preocupada com a descrição verossimilhante do fato, antiquários, de outro, homens cultos.

Na teoria do conhecimento há uma relação entre Realidade - Percepção - Imagem que aos poucos foi se naturalizando como a simples dicotomia da realidade em contraponto à imagem, como se a segunda fosse uma imagem 
enganosa do mundo, onde a certeza e o sentido unívoco do real fosse atingível apenas com a retirada do véu da subjetividade e ele descansasse sobre valores objetivos elencados sob a continuidade das substâncias. Benjamin, que toma o mundo como linguagem, ou para ser mais preciso, toma que os elementos do mundo da vida só são captados a partir da linguagem, devido a sua herança Kantiana, rompe com a certeza dicotômica entre Realidade X Imagem. Uma vez que a Realidade carrega em si uma série de aparatos que são dispostos no conto de Woolf, sempre que se trata da realidade, algumas características surgem dispostas em várias imagens que se ligam à ela: $A$ incerteza que engendra a constante questão sobre o que é a marca e a constante possibilidade de vir a conhecer que emula em si um conhecimento; a trivialidade como "uma coleção de grandes cachimbos de barro Tudor, uma peça de cerâmica romana, mais a taça em que Nelson bebeu vinho - para provar não sei bem o que." (WOOLF, 1994, 81) E a sensação de tranquilidade em relação a impossibilidade de não se conhecer uma coisa, mas ter domínio sobre ela, "Deve haver um livro a respeito. Algum antiquário deve ter desenterrado os ossos espalhados e lhes dado um nome..." (WOOLF, 1994, 81) ou ainda a possibilidade de ter a resposta para o que é a marca na parede, mas esta resposta não dizer nada:

Não, não, nada está provado, nada se conhece. Se eu me levantasse
nesse exato instante e me certificasse de que a marca na parede é de
fato - o que devo dizer? - a cabeça de um velho prego gigantesco,
fincado ali há 200 anos, e que agora devido a paciente faxina de muitas
gerações de criadas, mostrou a cabeça acima da camada da pintura,
e agora toma conhecimento da vida moderna à luz da lareira numa sala
de paredes brancas, que vantagem isso me traria? Que conhecimento?
Matéria para especulações anteriores? (WOOLF, 1994, 81)

Esses elementos são formadores de um material componente das estruturas ontológicas. Essa ontologia, que se manifesta de modo acachapante, se insere em um vasto debate sobre a sua valoração dessa ontologia e sobre seus efeitos. No mundo da política um debate que foi tomado alguns anos depois da morte de Woolf e Benjamin (1941 e 1940 respectivamente) foi feita já no pós guerra em relação â validade do estudo sobre e do pensamento desenvolvido ante uma publicidade, onde se destacam as apreensões de Heidegger que diz "O obscurecimento está normalmente ligado ao espaço público" e essa 
afirmação desenrola uma condenação ao espaço público e de tudo o que se desenvolve nele.

O pensamento heideggeriano se volta contra 0 isolamento e 0 silenciamento do Dasein dentro de uma estrutura ontológica, que ao se valer da perenidade formadora, executa a manutenção deste isolamento. Jeffrey Barash aponta ainda que o "Obscurecimento [Em Heidegger] está ligado, no essencial, à publicidade enquanto estrutura do ser-no-mundo" (WOOLF, 1994, 68), isto é, à mundanidade - resultado da relação entre publicidade e o obscurecimento uma vez que ela funciona como a estrutura ontológica do Dasein. Essa mundanidade do mundo é a condição para toda a relação significativa com as coisas e com o Dasein de outrem. Para Barash, a mundanidade denunciada no pensamento Heideggeriano funciona como o invólucro que mantém o Dasein em seu isolamento, mas também como uma estrutura de ação e interação falseada e enganosa.

Barash desenvolve a noção de que sendo a mundanidade do mundo, a estrutura ontológica do Dasein, ela se articula a partir do mundo circundante (Alltägliche Um) com o quotidiano (Mitwelt) em uma ação relacional onde o Dasein "se comporta de forma Frequente e Imediata." (BARASH, 1998, 69) Expondo assim a complexidade disposta por Heidegger em sua negativa do mundo público: Por conta de sua participação na estrutura ontológica do Dasein, o público, lugar onde o político se realiza, não pode contar dentro das considerações uma vez que ele se torna um dos elementos de afastamento e isolamento do Dasein, bem como, o elemento que por excelência seria responsável pela realização do obscurecimento.

O político é subsumido em Heidegger pelo fato dele ser a articulação pela qual a mundanidade do mundo agiria e tornaria prático a (1) impossibilidade do Dasein ser visto na esfera do mundo e (2) mesmo sendo visto, não poder se realizar de modo pleno, uma vez que o invólucro da mundanidade o mantém isolado dentro de uma imersão - sempre inautêntica, segundo Heidegger - nos elementos formadores dessa estrutura ontológica, isto é, os constructos e estruturas de explicação de mundo que se baseiam na perenidade e na 
continuidade infinita de sua duração, fator esse que para Heidegger soa como uma farsa e uma dissimulação do Dasein, uma vez que a única possibilidade de observação deste é na constância do acontecer do cotidiano.

Farsa, pois as estruturas e instituições que se mostram perenes não podem existir, uma vez que o cotidiano é o próprio acontecer, constante, inapreensível em uma longa duração e desprovido de um sentido que una o princípio e o fim, mas, antes de tudo, o acontecer. A dissimulação do Dasein por conta do engano explicativo que produz um sentido para o mundo que (1) oculta o constante acontecer e esconde a finitude dos acontecimentos e a finitude do próprio Dasein e das coisas assim (2) superpõem-se como uma explicação do real funcionamento do mundo. E a partir disso que há a necessidade da negação do político e, por sua vez, de toda a estrutura ontológica do Dasein.

É interessante notar que Hannah Arendt, a fim de salvaguardar a validade do pensamento Heideggeriano no contexto do pós guerra, aponta uma outra direção dentro do pensamento do filósofo, onde a autora argumenta que o real problema em relação ao público não é a inautenticidade vinda da perenidade da mundanidade do mundo.

Para Arendt há uma constante mais perigosa que é a destruição do mundo público. Como crítica, mas ainda com intento de salvar seu antigo mestre, Hannah Arendt contorna a proposta de observar a estrutura ontológica do Dasein como uma dissimulação e a retoma como um lugar seguro para a existência humana frente ao mundo, uma vez que a autora afirma que a dissimulação do Dasein é mantida, pois pensar dentro do terreno da autenticidade é pensar no fim da vida:

\begin{abstract}
A perenidade do mundo não se origina, para Arendt, numa interpretação inautêntica do Dasein que se dissimula a sua própria finitude. Designa, pelo contrário, o próprio lugar em cujo o seio a existência humana se protege e se preserva: neste sentido o "Público" faz apelo a um mundo comum, no qual se enraíza a vita activa nos seus diferentes modos de trabalho, de fabricação e de ação propriamente política. (ARENDT apud BARASH, 1998, 79-80)
\end{abstract}

A passagem é interessante, pois notamos que há ainda uma possibilidade de contorno sem deixar de ser crítico a respeito da ausência do político em Doutorando (CNPQ) no Programa de pós-graduação em História Social da Cultura da Pontifícia Universidade Católica do Rio de Janeiro. Brasileiro, reside em Rio de Janeiro-RJ. E-mail: 
Heidegger, uma vez que as dissimulações e enganos causados pela estrutura ontológica do Dasein estariam ligados a uma necessidade de nivelamento terraplanagem - do espaço público a fim de toma-lo como um local seguro de ação. O que seria uma opção não contemplativa e não estética para a ação no mundo público, seja ela em pensamento político ou na própria política9 . Colocando Heidegger contra a parede, uma vez que, retomar o espaço público e a política é uma tarefa do pensamento, para a sua salvaguarda e para impedir a destruição e o apagamento de ambos, dessa forma a autora determina criticamente que a postura Heideggeriana se torna uma atitude perigosa para 0 espaço público uma vez que "Com cada retirada deste gênero produz uma perda no mundo quase demonstrável: o que é perdido é o intervalo específico e habitualmente insubstituível que se deveria ter formado entre este homem e os seus semelhantes." (ARENDT apud BARASH, 1998, 81)

Dessa forma, mesmo tomando o obscurecimento como uma ferida no caráter público, como a autora toma em sua paráfrase "A luz do público obscurece tudo" (ARENDT apud BARASH, 1998, 68), ela não quer dar continuidade à crítica e o consequente abandono do espaço público em Heidegger, mas antes de mais nada compreender que esse obscurecimento do mundo não é um sintoma causado pelo público, mas sim um diagnóstico de uma condição limitada de pensamento que não consegue ligar o Dasein está, não na historicidade deste, mas antes de tudo, na sua ligação com movimentos históricos, cujo final aporético a autora encontra na modernidade, segundo Barash,.

Esse intervalo a respeito do pensamento de Heidegger nos é interessante por propiciarmos uma visão dupla, por um lado temos que a ontologia do mundo é sempre um problema para quem está lidando com ele, uma vez que os fenômenos do mundo passam pela obscuridade de estarem se desenrolando no mundo político, a corrente de acontecimentos que a realidade traz consigo

\footnotetext{
${ }^{9}$ Diferente do que aparece em Heidegger a experiência estética e a mística são as únicas saídas para a resolução da angústia (Angst) que uma vez instaurada, rompe com os tratados e dissimulações do quotidiano comum propiciado pela estrutura ontológica do Dasein.
} 
ocultam esses acontecimentos em um véu de sentido único. Benjamin, apesar de ter uma visão oposta a Heidegger, ao creditar na experiência parte da possibilidade de quebrar essa unidade do real e a coerência sequencial do mundo da vida, se direciona para o mesmo instante de condenação do sentido de real que a mundanidade/cotidiano expressam, como o autor trata em suas Teses Sobre o Conceito de História e na sessão $\mathrm{N}$ das Passagens, temos a possibilidade de quebrar essa continuidade do real a partir da imagem/metáfora, mas também a necessidade de escovar a história a contrapelo, se quisermos obter alguma resposta que vá além do simples colecionismo político da consequente justificação da ontologia do mundo.

O que nos remete a outra gama de pessoas que Woolf aponta, as que operam dentro da compreensão de imagem, eles que se ligam a uma busca profunda de conhecimento partindo de camadas da linguagem que não se integram a convenções que alimentam esse real, mas se necessário estão dispostos a sacrificar o sentido pleno que o real tem em nome do verdadeiro conhecimento:

\footnotetext{
Mas o que é conhecimento? O que são os nossos homens cultos senão descendentes de feiticeiros e ermitãos, que se agacharam em cavernas e bosques cozendo ervas, interrogando megeras $e$ decifrando a linguagem das estrelas? Quanto menos nós os glorificamos tanto mais nossas superstições diminuem e aumentam nosso respeito pela beleza e pela saúde mental... sim, pode pensar em um mundo bem aprazível. (WOOLF, 1992, 81)
}

Essa passagem nos é vital para compreendermos o estatuto que a imagem e todos os que se colocam no seu lado para pensar, tem. Por um lado, o grupo desenhado pela autora inglesa é formado pelos membros que se colocaram à parte dessa sociedade, de modo que eles gozam, como no conto de Fiódor Dostoiévski - Bobok (DOSTOIÉVISKY, 2012) - como os que se retiraram das estruturas de mundo ontologicamente dadas e disponíveis para se viver fora de sua própria autenticidade e se colocam dentro de uma instância ética permeada por uma constante proximidade com a propriedade ôntica e autentica do Dasein no conto russo; aqueles que mergulham nessa condição, de pôr-se para fora da estrutura de modo total se tornam incompreendidos mesmo 
quando as estruturas de auto proteção da ontologia que isola o Dasein já não são mais importantes, como é o caso de um dos personagens do conto, Platon Nikoláievitch que depois de dar as coordenadas do que seria o pós morte para seus pares fantasmas falecidos, avançou nos seus estudos e o quanto mais avança, só conseguia dizer entre longos silêncios a palavra Bobók que longe de ter seu sentido estrito (cuja tradução significa fava) tinha uma relação com o nãosentido do mundo, palavra essa que já atormentava o protagonista

O amigo está certo. Uma coisa terrível está acontecendo comigo. O caráter mundano, a cabeça doendo. Começo a ver e ouvir umas coisas estranhas. Não são propriamente vozes, mas é como se estivesse alguém ao lado: Bobók, Bobók, Bobók!

Que Bobók é este? Preciso de divertir. (DOSTOIÉVISKY, 2012, 12)

O personagem já está inscrito fora da ontologia, ainda que esteja preso nela, mas pelo seu fazer literário se aproxima mais do não sentido do mundo, o que torna a existência tensa por conta do seu enfrentamento com a vida cotidiana e inautêntica e mesmo pela reação que as pessoas, imersas nessa mundanidade esboçam, quando são confrontadas e expostas.

Ou ainda, no sentido de mundo, como um aglomerado resistente a mudanças como é apresentado por Dostoiévski, a perturbação do momento em que se percebe toda a farsa cotidiana, toda a farsa da existência em um mundo que não sabendo lidar com a proximidade constante da morte cria estruturas de desfalque em relação a realidade e sua existência. No momento em que se percebe isso e que o instante da morte é reconhecido como apenas mais uma estrutura que copia essa mundanidade inautêntica e que pela primeira vez podese romper com ela e se viver uma vida "sem nenhuma vergonha! Ah! Quando começaremos a não ter vergonha de nada!" (DOSTOIÉVISKY, 2012, 40) Mas por uma razão mundana e trivial, sai desse momento sem as amarras da ontologia justificadora da vida e retorna ao mundo da inautenticidade: " $E$ eis que de repente espirrei. Aconteceu de forma súbita e involuntária, mas o efeito foi surpreendente: Tudo ficou em silêncio, exatamente como no cemitério, desapareceu como um sonho." 
Voltando à Woolf, tem-se então uma seleção de pessoas que vivem suas vidas em consequente interrogar-se sobre a natureza do conhecimento e não buscam conhecimentos práticos de resposta imediatas, este conhecimento buscado é localizado fora das estruturas normativas que alimentam a ontologia que no conto de Woolf são estruturas de estabilidade e garantidoras da saúde mental e da própria felicidade, "Eis a natureza uma vez mais no seu velho jogo de auto preservação"(WOOLF, 1992, 82) Ao passo de que a busca pelo real conhecimento tira esse véu de auto proteção que o Dasein é envolto em seu isolamento, e ao atingir o instante crítico, para usar os termos de Benjamin, do conhecer e do "conhecer o conhecer" há apenas a instabilidade e o não-sentido que imperam no real. Impossibilitando a felicidade e a complacência que o mundo tem, uma vez que se se reconhece em um terreno instável, sem garantias e reconhecendo a dor de gritar para um universo que não responde. Esse resguardo só é atribuído a primeira gama de pessoas, as que se ligam ao conhecimento ontologicamente constrangido. Os que se arriscam a observar a imagem em sua realização instantânea estão abertos a todos os sofrimentos que ela traz e ao perigo constante de ser tomado como alguém que preferiu se isolar:

Entendo o jogo da natureza - sua capacidade rápida de entrar em ação para interromper um pensamento que ameaça irritar ou provocar dor. Disso, suponho eu, decorre o nosso leve desprezo pelos homens de ação - homens, assim admitimos, que não pensam.

Esse mecanismo de auto-preservação é exatamente o mesmo que Hannah Arendt lança mão para empreender a defesa de Heidegger e sua condenação sobre o espaço público: uma vez que o homem esteja atuando no espaço público é necessário esse apagamento da reflexividade, senão, nenhuma ação seria possível. (BARASH, 1998, 81) Woolf compreende que essa forma de autopreservação é um elemento natural formado a partir de uma resposta ontológica de autopreservação. Em contraponto a isso só há a instabilidade e o não-sentido que é o real estado do real. Essa instabilidade só se mostra no contrapelo, na reflexão e no instante da imagem.

Por fim, a personagem decide, depois de formular uma torrente de pensamentos que formam uma bela imagem sobre uma árvore e o ambiente natural e social que a cerca, essa imagem expõe uma figuração de aderência 
onde a personagem alinha toda a Stimmung da árvore e da madeira e de toda a reflexão que isso causa, "Nada consigo reter. Tudo se move, cai, desliza, desaparece..."(WOOLF,1992, 83) e que não pode ser totalmente percebida, uma vez que não há um unificador, um sentido, a menos o que será automaticamente constituído pela consciência de vigília, do contrário, apenas há a dispersão de elementos. Mas não sabemos plenamente o que é essa dispersão por dois motivos, primeiro que sempre estamos imersos em uma constante produção de sentido e esta dispersão só se mostraria de modo instantâneo, e por outro, mais simples de compreender, que esta dispersão é interrompida pela mundanidade dos que cercam a personagem principal: uma grande convulsão de matéria. Alguém se debruça e me diz

- 'Vou sair para comprar jornal'

- 'Ah, é?'

- 'Sei que não vale à pena... não acontece nada. Guerra mais excomungada! Que vá para o diabo! De qualquer maneira, não vejo por que deveríamos ter uma lesma na parede.'

Ah, a marca na parede! Era uma lesma.

(WOOLF, 1992, 83)

Nesse sentido, é interessante notar que a marca na parede, antes de ser notada como uma lesma, ou seja, colocada em um sentido estrito que não traz informação nenhuma, se mostra como a Gestaltete como apresenta Walter Benjamin, como um enformamento que propiciando uma imagem tensionada aliada à fantasia, permite a criação de algo novo e de um conhecimento que não se explica somente no bojo de um determinismo empírico. A marca na parede funciona como um elemento intelectivo que vai desdobrando a experiência imagética, para além dela mesma, por um lado enformando, e transformando, por outro, abrindo espaço para a ação como um núcleo luminoso que vai jogando luz para os lugares a serem preenchidos pela criação.

O que pretendi demonstrar, com esse texto, são as interações que uma geração enfrentou em relação à linguagem, e como isso reverbera em uma temática que, quando vai sendo desdobrada com um determinado aparato, chega a situação demonstrada por Iser, e pelo próprio Walter Benjamin, de uma obra que se abre metacriticamente para sua origem no terreno do ficcional e 
como esse campo interage - do particular ao geral - em um determinado ambiente.

É estranho pensar que a literatura possa desdobrar o pensamento filosófico, mas a guisa de Benjamin, pensar é sempre conjugar o Passado e o Futuro em um só lugar, sem querer prender a nenhum dos dois. Woolf, tanto como Dostoiévsky, enfrenta o problema que bate na porta dos que conjuram a literatura. Se movem no expresso reconhecimento da inautenticidade do mundo, nas estruturas "idiotas" ou de simples "ação" e em como os homens agem nessa e para essa estrutura (ontológica) que valida o homem frente ao mundo e a sua própria autopreservação frente à constância do peso da morte.

\section{REFERÊNCIAS}

BARASH, Jeffrey. Heidegger e o seu século. Lisboa: Instituto Piaget, 1998 BENJAMIN, Walter. Obras escolhidas: magia e técnica, arte e política. São Paulo: Brasiliense, 1996.

. Origem do drama barroco alemão. Tradução, apresentação e notas de Sérgio Paulo Rouanet. São Paulo: Brasiliense, 1984. . Passagens de Walter Benjamin. TIEDEMANN, Rolf; BOLLE, Willi; MATOS, Olgária Chaim Feres (Org.). Trad. Irene Aron e Cleonice P. B. Mourão. Belo Horizonte: UFMG/Imprensa Oficial de São Paulo, 2006 . Rua de Sentido Único e infância em Berlim por Volta dos 1900. Lisboa: Relógio D’Água, 1992. 
DOSTOIÉVSKY, Fiodor. Bobók. Tradução: Paulo Bezerra. São Paulo: Editora 34, 2012

GAGNEBIN, Jeanne Marie. Do conceito de mímesis no pensamento de Adorno e Benjamin. Perspectivas: Revista de Ciências Sociais, v. 16, p. 6786, São Paulo, 1993.

ISER, Wolfgang. O Fictício e o Imaginário: Perspectivas de uma antropóloga literária. Rio de Janeiro: Ed.UERJ, 2013.

KANT, Immanuel. Crítica da Faculdade de Julgar. Tradução Fernando da Costa Mattos. Petrópolis: 2016.

WOOLF, Virgínia. Objetos Sólidos. Tradução: Hélio Pólvora - São Paulo:

Siciliano, 1992. 